\title{
ANÁLISE GEOAMBIENTAL DOS SETORES DE ENCOSTA DA ÁREA URBANA DE SÃO VICENTE-SP
}

\section{Geographic environmental analysis of hillside sections in the urban area of São Vicente-SP}

\author{
Raul Reis Amorim \\ Mestrando em Geografia pela Universidade Estadual de Campinas (UNICAMP-SP) \\ raul_reis_amorim@ige.inicamp.br \\ Regina Célia de Oliveira \\ Professora Doutora do Departamento de Geografia, Instituto de Geociências da \\ Universidade Estadual de Campinas (UNICAMP-SP) \\ reginacoliveira@ige.unicamp.br
}

Artigo recebido para publicação em 18/03/2007 e aceito para publicação em 16/08/2007

RESUMO: As encostas constituem uma forma de relevo complexa, caracterizada por uma acentuada fragilidade natural, que sob a interferência humana pode sofrer a aceleração de processos erosivos e escorregamentos. A ocupação desordenada destes ambientes provoca riscos às atividades econômicas e à própria vida dos seres humanos. O objetivo deste trabalho é a realização de uma análise geoambiental das encostas da área urbana de São Vicente-SP. Ele está dividido nas seguintes etapas: inventário dos atributos naturais e sócio-demográficos da área em livros, periódicos, mapas e na base de dados do Instituto Brasileiro de Geografia e Estatística - IBGE (regiões censitárias); trabalhos de campo para identificar o grau de risco das encostas; elaboração do mapa de fragilidade a escorregamentos da área urbana de São Vicente. Os setores de encostas estão ocupados parcialmente, pois uma área significativa continua coberta por vegetação. As áreas já urbanizadas são classificadas como estruturadas preferencialmente habitadas pela população de melhor poder aquisitivo. A área tem risco iminente a escorregamentos, que a depender da intensidade podem gerar risco de vida $e$ prejuízos materiais.

Palavras-chave: encostas; ocupação; fragilidade; escorregamentos.

ABSTRACT: Hillsides constitute a complex relief shape, characterized by an accentuated natural fragility, which can suffer the acceleration of erosion and landslide under human interference. The disordered occupation of these environments causes risks to economical activities and to human beings' own life. The objective of this work is the accomplishment of an environmental analysis of hillsides in the urban area of São Vicente-SP. It is divided in the following stages: inventory of the natural, social and demographic attributes of the area in books, newspapers, maps and in the database of Brazilian Institute of Geography and Statistics - IBGE; field works, in order to identify the risk degree of hillsides; elaboration of the map of fragility to landslides of the urban area of São Vicente. The sections of hillsides are partially occupied, because a significant 
area is still covered by vegetation. The areas which are already urbanized are classified as structured, and are mainly inhabited by the population of better purchasing power. The area has imminent risk of landslides which, depending on its intensity, can cause life risk and material damages.

Keyword: hillsides; occupation; fragility; landslides.

\section{INTRODUÇÃO}

Os ambientes foram e são construídos durante toda a história do planeta Terra, tanto pela ação natural, como pela ação antrópica. Para compreender os ambientes atuais não basta apenas entender as condições ambientais hoje, mas sim analisar a evolução deste ambiente durante as diversas Eras Geológicas. As encostas, por exemplo no caso que será abordado, evidenciam as mudanças climáticas, a dissecação do modelado, as mudanças no escoamento das águas superficiais e subsuperficiais, a alteração dos biomas, e a ocupação antrópica.

No que toca a questão da ação antrópica, as áreas preferenciais de ocupação das sociedades sempre foram às áreas mais planas, geralmente planícies ou áreas planas de planaltos, que facilitavam sua fixação, seja na prática de atividades agrícolas ou na instalação de atividades urbanas.

No território brasileiro ocupação de encostas datam do período colonial, já que as vilas e cidades eram edificadas em elevações objetivando proteção. Uma das localidades onde o processo de ocupação de encostas é secular é na cidade de São Vicente(SP). Sendo uma das duas Capitanias Hereditárias que prosperaram com o cultivo de cana-de-açúcar no Brasil-Colônia, destaca-se no contexto nacional por constituir o primeiro núcleo habitacional, fato que lhe deu o título de "Célula Mater da Nacionalidade".

O processo de (re)produção do espaço de São Vicente ganha velocidade depois de 1950, com o processo de industrialização e urbanização do Estado de São Paulo. A partir das décadas de 1960 e 1970 o turismo foi o principal agente da expansão da área urbana, que levou a uma especulação imobiliária, levando a uma verticalização de toda a área próxima à orla que abrange as áreas de planícies como os Morros Residuais.

A ocupação dos Morros Residuais da área urbana de São Vicente está acentuando-se com o crescimento populacional das últimas décadas, fruto do próprio crescimento vegetativo da população local e do fluxo de imigrantes que se deslocaram para o litoral em busca de melhor qualidade de vida, novas oportunidades de emprego e investimentos dentre outras causas.

As principais conseqüências desse processo de antropização desordenado é a ocorrência de inúmeros impactos ambientais. Podemos citar dois exemplos: o desmatamento que expõe as encostas aos agentes intempéricos, e os cortes nas encostas de maneira indevida, que sem o necessário apoio técnico, alteram o nível de base destas, desencadeando conseqüentemente a aceleração de processos erosivos e escorregamentos.

As encostas constituem uma forma de relevo básica, presente em qualquer parte da superfície terrestre, e, portanto, têm sido analisadas exaustivamente pelos geomorfólogos. Além disso, afetam diretamente as atividades humanas, tais como agricultura, construção de rodovias e ferrovias, expansão urbana, mineração, atividades de lazer etc. Dessa forma, seu estudo tem grande importância, porque seu mau uso pode provocar riscos às atividades econômicas e a própria vida dos seres humanos (GUERRA, 2003).

Como as atividades econômicas desenvolvi- 
das pelo homem estão situadas sobre alguma forma de relevo e algum tipo de solo, o estudo das formas de relevo e dos processos associados, principalmente na área de encostas, é bastante útil. Pois possibilitou a prevenção de problemas ambientais que podem ter uma abrangência mais catastrófica ou de menor impacto, dependendo do tipo do uso e manejo do solo e, também, das características do meio físico (ARAUJO; ALMEIDA \& GUERRA, 2005).

Assim estudar a dinâmica e evolução das encostas somadas ao processo de ocupação dos morros de São Vicente é importante, primeiro, por ser um dos municípios significativos demograficamente da Região Metropolitana da Baixada Santista; e segundo, porque as recentes transformações no uso da terra, não só do município de São Vicente, mas também em toda a Baixada Santista, ocasionam uma grande pressão ao meio ambiente. Analisando como se dá esse processo de ocupação, e quais as áreas mais susceptíveis a escorregamentos é possível contribuir para a organização de medidas de prevenção ao uso desse espaço, de forma a minimizar acidentes que possam trazer danos ambientais com prejuízos materiais e mesmo de vida humana.

O objetivo geral deste trabalho, que toma como objeto de estudo a área urbana de São VicenteSP é a identificação das áreas com fragilidade a escorregamentos. Para atingir tal objetivo, realizouse um levantamento dos atributos naturais e socioeconômicos e demográficos da área de estudo. Também se realizou trabalhos de campo para identificar o grau de risco de cada encosta de São Vicente e coletou-se dados referentes aos níveis de ocupação da área in locu, bem como pertencentes na base de dados do Instituto Brasileiro de Geografia e Estatística (IBGE) - setores censitários do município em estudo.

\section{MATERIAL E MÉTODOS}

\section{1. Área de Estudo}

A cidade de São Vicente está situada a $24^{\circ} 00$ S e $46^{\circ} 30^{\prime} \mathrm{W}$, no centro do litoral paulista, com uma distância de aproximadamente $71 \mathrm{~km}$ da capital e com altitude em torno de 10 m (Figura 01). Ao integrar a Região Metropolitana da Baixada Santista, limita-se com os seguintes municípios: a norte com São Bernardo do Campo; a nordeste com Cubatão; a leste com Santos; ao sul com Praia Grande; a sudoeste com Mongaguá; e a oeste com Embu Guaçu.

A área de estudo apresenta uma superfície total de $146 \mathrm{~km}^{2}$, sendo que a posição insular representada pela Ilha de São Vicente, abrange $18 \mathrm{~km}^{2} \mathrm{e}$ é separada da área continental, que possui $117 \mathrm{~km}^{2}$, tendo ainda $11 \mathrm{~km}^{2}$ de canais e rios.

\subsection{Fundamentos Metodológicos}

A metodologia proposta para este trabalho é o método geossistêmico, sob a ótica da Geoecologia da Paisagem preconizada por Rodriguez; Silva e Cavalcanti (2002). O método geossistêmico tem como objeto de estudo os geossistemas, sendo estes definidos como um conjunto interrelacionado de formações naturais e antropo-naturais, podendo-se considerá-la segundos os autores (op. cit):

- um sistema que contém e reproduz recursos;

• um meio de vida e da atividade humana;

- um laboratório natural e fonte de percepções estéticas.

Tendo os geossistemas como unidades naturais integrais, podem-se distinguir suas modificações e transformações como resultado das ações dos diferentes tipos de ocupação.

Destarte este trabalho é alicerçado em uma análise sistêmica, fundamentando-se numa análise integrada dos componentes antrópicos e naturais a partir de uma caracterização socioeconômica e geoecológica, que subsidiará a elaboração de uma documentação temática e formulação de textos científicos que subisidiará o planejamento territorial. 


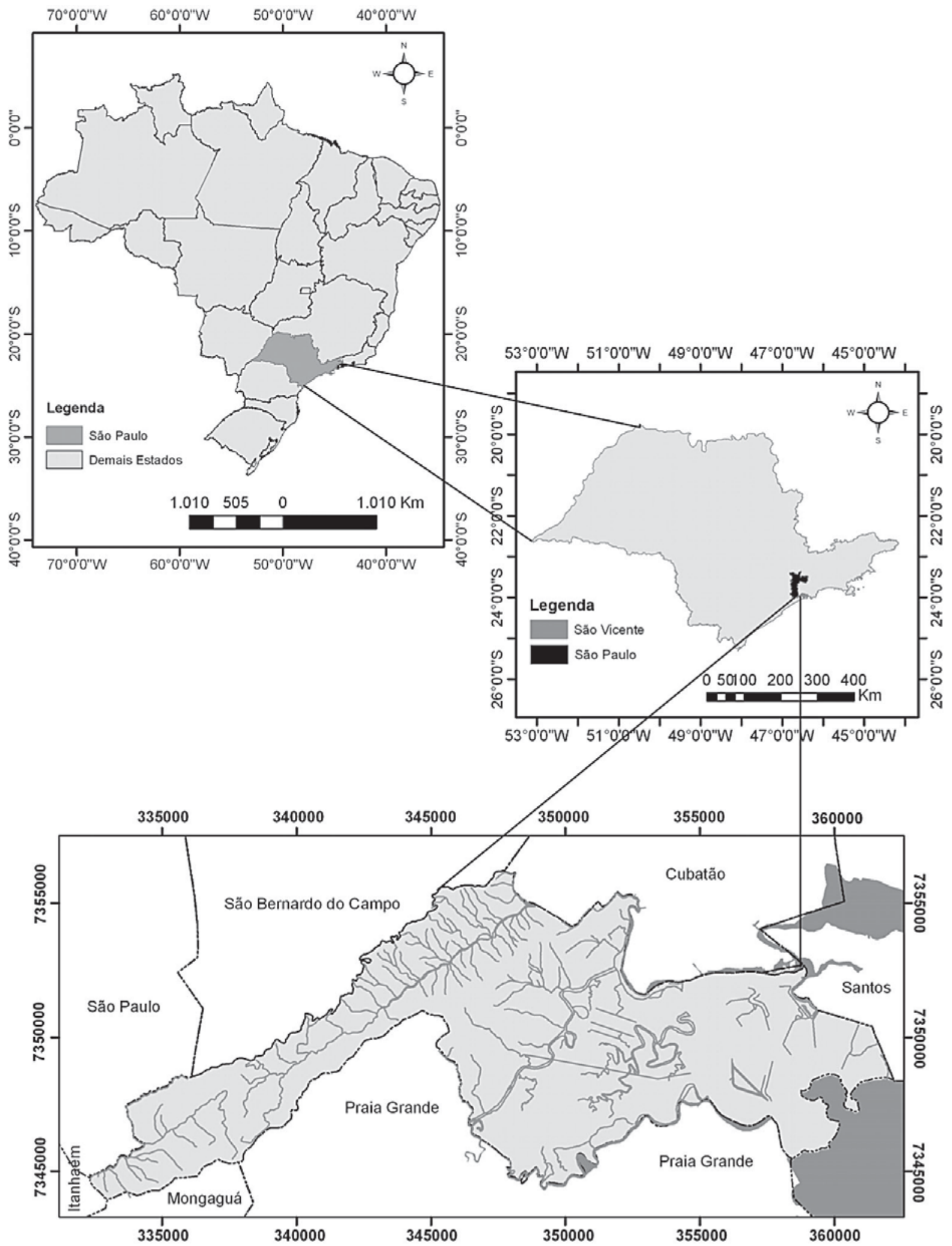

Figura 1. Localização do município de São Vicente no Estado de São Paulo.

Elaboração: Raul Reis Amorim

Fonte: IBGE (2000)

Sociedade \& Natureza, Uberlândia, 19 (2): 123-138, dez. 2007 
Para Rodriguez (1990) a análise sistêmica baseia-se no conceito de paisagem com um "todo sistêmico" em que se combinam a natureza, a economia, a sociedade e a cultura, em um amplo contexto de inúmeras variáveis que buscam representar a relação da natureza como um sistema e dela com o homem.

Nesse contexto, a paisagem é entendida como um sistema aberto, que se encontra em constante inter-relação com as paisagens circundantes através da troca de matéria e energia.

Para Mateo Rodriguez; Silva e Cavalcanti (2002), o procedimento científico de regionalizar as paisagens consiste em determinar o sistema de divisão territorial de unidades espaciais de qualquer tipo (administrativas, econômicas, naturais etc.) em escala global, regional e local.

A regionalização físico-geográfica (geoecológica ou de paisagens) consiste na análise, classificação e cartografia dos complexos físico-naturais individuais, tanto naturais como modificados pela atividade humana e a compreensão de sua composição, estrutura, relações, desenvolvimento e diferenciação.

O critério de distribuição desses complexos não é a semelhança, mas a inseparabilidade, as relações especiais e o desenvolvimento histórico. Cada unidade tem seu próprio nome e uma única área territorial.

Este trabalho propõe realizar a diferenciação da paisagem em escala local. A diferenciação em nível local, ou topológico, manifesta-se em todos os componentes naturais. O relevo como fator geoecológico de redistribuição de calor e umidade, tem papel significativo na distribuição das respectivas unidades de diferenciação em nível local com enfoque histórico-antropogênico na análise da paisagem.

O estudo da história antropogênica da formação das paisagens atuais é importante, pois os resultados da utilização econômica em grande parte as propriedades relevantes para o homem, como o caráter estável dos processos antropo-naturais, os problemas ecológicos que surgem na assimilação, ocupação e apropriação dos geossistemas e as vias de sua solução.

A metodologia proposta por Rodriguez (1994); Mateo Rodriguez; Silva e Cavalcanti (2002) envolve os procedimentos quais sejam, a organização do projeto, inventário dos componentes naturais caracterização geoecológica; e o inventário dos componentes antrópicos - caracterização econômica. A integração dessas informações subsidiará a fase analítica que consiste na análise dos resultados dos indicadores ambientais que, por sua vez subsidiarão a fase posterior do diagnóstico. Com isso constitui-se uma síntese dos resultados dos estudos, com a indicação dos principais problemas ambientais, o que possibilita a caracterização do cenário atual, entendido como geoambiental.

\subsection{Procedimentos Metodológicos}

O presente trabalho foi elaborado através dos seguintes procedimentos: (a) levantamento e produção cartográfica; (b) visitas a campo; e (c) consultas a documentos públicos e levantamento bibliográfico.

O levantamento e produção cartográfica subdividiram-se na organização das Cartas Topográfica e Drenagem, Geológica (MARTIN e SUGUIO, 1978); Formações Superficiais (MACIEL, 2001); e Pedológica (IAC, 1999; MACIEL, 2001) na escala 1:50.000, no software Arc Gis 9.1; e a elaboração das Cartas Hipsométricas e Classes de Declividade com a interpolação dos layers "curvas de nível” e "pontos cotados" no software Arc Scene na escala 1:50.000. Também se elaborou as Cartas Geomorfológica, Compartimentos Geomorfológicos; Cobertura Vegetal e Uso da Terra de 2002, resultante da análise visual de imagens de satélite Cibers de 2004 e a análise e interpretação de fotografias aéreas de 1962 e 1994, com escala de 1:25.000, fornecidas pelo Laboratório de Sensoriamento Remoto e Aerofotogrametria da Universidade de São Paulo (USP), e fotografias aéreas de 2002 adquiridas pelo Núcleo 
de Estudos Litorâneos (NEL) do Laboratório de Geomorfologia, do Instituto de Geociências da Universidade Estadual de Campinas (UNICAMP).

As visitas a campo objetivaram levantar informações referentes à fragilidade das encostas a escorregamentos da área estudada. Inicialmente, consultou-se os arquivos da Defesa Civil de São Vicente para identificar as áreas que já ocorreram escorregamentos. Portando uma ficha de observação e equipamentos técnicos (clinômetro, trena, trado, máquina fotográfica digital e GPS) levantou-se dados referentes (a) a condicionantes a escorregamento, (b) evidências de movimentação do material, (c) ação da água nas encostas, (d) características da vegetação, (e) evidencias de instabilização e (f) características nos níveis de ocupação da área. Estas informações subsidiaram a elaboração do "Mapa de Fragilidade a escorregamentos dos setores de encosta da área urbana de São Vicente-SP”.

Realizou-se ainda uma consulta dos documentos históricos em posse do Arquivo Público Municipal, Defesa Civil e museu "Casa Martin Afonso” em São Vicente-SP. Também se consultou a obra "A história de São Vicente contada através dos Bairros” publicada pela Secretaria de Educação de São Vicente (RAMALHO et al, 2000), bem como jornais e periódicos foram examinados a fim de subsidiar as discussões. Outro documento consultado foi o relatório do Censo Demográfico do Instituto Brasileiro de Geografia e Estatística (IBGE), realizado em 2000. Consultou-se, por fim, os dados das regiões censitárias que abrangiam as áreas de encosta da cidade.

\section{DIAGNÓSTICO DOS SETORES DE ENCOSTA DA ÁREA URBANA DE SÃO VICENTE-SP}

Aárea urbana de São Vicente abrange a área de $45,37 \mathrm{~km}^{2}$, sendo esta subdividida em áreas planas e suavemente onduladas e morros residuais que apresentam área de 4,66 km². Um dado interessante é que $20 \%$ dos Morros Residuais estão ocupados por área urbana e o restante, cerca de $80 \%$, apresenta cobertura vegetal primária, secundária ou cultivo agrícola como bambuzais e bananeiras.

As encostas da área urbana de São Vicente apresentam como característica: a baixa amplitude relativa do relevo, não ultrapassando o patamar de 200 metros, sustentados por uma litologia composta basicamente por embasamentos cristalinos (SUGUIO e MARTIN, 1978). Os morros situam-se predominantemente na área insular do município, estando apenas o Morro do Xixová situado na área continental (Bairro Japuí). As demais elevações situam-se nos bairros Gonzaguinha (Morro dos Barbosas), Itararé (Morro Itararé e Ilha Porchat), e Voturuá/Vila Independência (Morro Voturuá).

O Bairro Gonzaguinha abrigou a primeira Vila do Brasil, fundada em 1532. Segundo o historiador Francisco Martins dos Santos, o primeiro núcleo de povoamento da Vila foi devastada pelo avanço do mar em 1542. A transgressão marinha na época destruiu a Casa de Câmara e Cadeia, a Casa do Conselho, o Pelourinho e a Igreja Matriz Nossa Senhora da Assunção, erguida por Martim Afonso de Souza com o auxílio do Padre Gonçalo Monteiro (RAMALHO et al, 2000).

Após a destruição da Vila de São Vicente, o processo de ocupação deslocou-se em direção ao atual centro da cidade, já que os processos morfogenéticos continuaram a atuar sobre orla marítima que passou a apresentar a configuração semelhante a atual a partir de 1624 . A retomada do processo de ocupação do bairro deu-se apenas a partir de 1878 (op. cit).

O Morro dos Barbosas situado no bairro pertencia a Caetano Barbosa até 1869, ano de seu falecimento. A área foi deixada de herança a sua filha Laurinda, que era casada com Francisco Xavier dos Passos (Chico Botafogo). Em 1887, Chico Botafogo doou à Prefeitura, uma área do morro para construção da primeira caixa reservatório de água da cidade (op. cit).

Na década de 1950, acelerou-se o desmata- 
Tabela 1. Caracterização Sócio-Demográfica dos setores de encosta da área urbana de São Vicente-SP.

\begin{tabular}{|c|c|c|c|c|c|}
\hline Variáveis & \multicolumn{5}{|c|}{ Número de domicílios } \\
\hline Moradores & $\mathrm{A}$ & $\mathrm{B}$ & $\mathrm{C}$ & $\mathrm{D}$ & $\mathrm{E}$ \\
\hline 1 morador & 22 & 60 & 428 & 60 & 68 \\
\hline 2 moradores & 39 & 60 & 428 & 108 & 127 \\
\hline 3 moradores & 15 & 28 & 249 & 116 & 187 \\
\hline 4 moradores & 15 & 33 & 184 & 135 & 188 \\
\hline 5 ou mais moradores & 13 & 21 & 237 & 156 & 204 \\
\hline Renda média & \multicolumn{5}{|c|}{ Número de domicílios } \\
\hline Até $1 / 2$ S.M. & 0 & 0 & 0 & 0 & 0 \\
\hline De $1 / 2$ a 1 S.M. & 7 & 0 & 56 & 56 & 23 \\
\hline De 1 a 2 S.M. & 12 & 8 & 85 & 71 & 28 \\
\hline De 2 a 3 S.M. & 11 & 9 & 120 & 73 & 44 \\
\hline De 3 a 5 S.M & 15 & 15 & 267 & 138 & 69 \\
\hline De 5 a 10 S.M. & 39 & 44 & 476 & 131 & 66 \\
\hline De 10 a 15 S.M. & 11 & 22 & 136 & 21 & 10 \\
\hline De 15 a 20 S.M. & 11 & 24 & 78 & 8 & 1 \\
\hline Mais de 20 S.M. & 9 & 46 & 74 & 19 & 3 \\
\hline Sem rendimento & 9 & 34 & 54 & 58 & 24 \\
\hline Distribuição Etária & \multicolumn{5}{|c|}{ Número de habitantes } \\
\hline População Jovem ( 0 a 14 anos) & 71 & 102 & 515 & 516 & 772 \\
\hline População Adulta (15 a 60 anos) & 214 & 343 & 2152 & 1375 & 1865 \\
\hline População Idosa (acima de 60 anos) & 52 & 62 & 575 & 185 & 294 \\
\hline
\end{tabular}

Legenda:

A - Morro dos Barbosas

B - Ilha Porchat/Itararé

C - Voturuá/Vila Independência

D - Japuí.

S.M. salários mínimos

Fonte: IBGE (2000).

mento das encostas do Morro dos Barbosas objetivando a construção de edifícios e residências. Até então, a ocupação do Morro dos Barbosas era restrita à base da elevação. A ocupação sem o devido planejamento desencadeou vários escorregamentos na área, destacando-se o ocorrido em 1966, quando o Edifício "Vista Linda” desabou por inteiro (COMDEC, 2007).

Tentando evitar novas catástrofes na área, em 1964, o vereador Jayme Houmeaux de Moura submeteu à câmara municipal de São Vicente a Lei que proibia a construção de edifícios com mais de dois pavimentos em todo o Morro (RAMALHO et al, 2000).

No Morro dos Barbosas residem 337 habitantes distribuídos em 124 domicílios, sendo que destes 92 são apartamentos e 32 são casas. Todos os domicílios são atendidos pelos serviços básicos de infra-estrutura, como a coleta diária de lixo, o abastecimento de água encanada, a ligação à rede geral de esgoto, a iluminação pública, e o acesso com ruas pavimentadas (IBGE, 2000). 
Na área verificou-se que uma parte das residências fica desocupada durante $\mathrm{o}$ ano, servindo como segunda residência nas épocas de férias e feriados prolongados. Os dados da Tabela 01 comprovam que a área é ocupada pelas populações de classe média e alta do município, pois a maioria das residências apresenta número reduzido de moradores, formando famílias não muito grandes. Cerca de 31,45\% das moradias apresentam renda média acima dos 5 salários mínimos enquanto 25\% das residências apresentam renda superior ou igual a 10 salários mínimos. Pode-se verificar que na área predominam moradores entre 15 e 59 anos (cerca de 63,5\% do total). Outro dado importante da área é o maior percentual de idosos dos setores de encosta de São Vicente, comprovando a afirmação do poder público municipal que afirma que a cidade atrai aposentados das diversas áreas do Estado que buscam na cidade melhoria da qualidade de vida após anos de trabalho.

O Morro dos Barbosas é definido como uma área de ocupação mista, pois apresenta ocupação urbana consolidada e com infra-estrutura e cobertura vegetal primária e secundária. As vistorias de campo foram realizadas na base da encosta (ao entorno da Rua João Pereira de Almeida) e no topo da encosta (na Rua Luiz Vaz de Camões, nas proximidades da SABESP e do Hotel Chácara do Mosteiro).

Na base da encosta a inclinação média da encosta natural está situada entorno dos $70^{\circ}$ e no talude de corte esta inclinação é de $90^{\circ}$. Os solos são pouco espessos com contato abrupto com a rocha sã. Também foram identificados matacões com fraturas não-alinhadas, que apresentam processo de intemperismo físico acelerado, conhecido popularmente como esfoliação tipo cebola.

Além da ocupação por residências na base da encosta, ocorreu a implantação do ponto turístico denominado Biquinha, nome dado por causa da bica de água mineral que aflora na área. No entorno da Biquinha verifica-se que as cicatrizes de deslizamento estão sendo cobertas pela vegetação rasteira. Uma evidência de instabilidade do material na localidade é a inclinação das árvores, típico indicador do rastejamento ou movimento de creep.

A área é sujeita a escorregamentos de proporções média e alta (Figura 02). Segundo a Defesa Civil, os principais eventos ocorreram no verão dos anos de 1995, 2003, 2004 e 2005. Em 1995, um movimento de massa soterrou toda a área da Biquinha, levando o governo municipal a promover a reconstrução da área, hoje equipada por estacionamentos e quiosques para atendimento ao turista (A TRIBUNA, 1995). Na área, foram construídas rampas para o escoamento das águas servidas e pluviais, a construção de muros de contenção no fundo de casas e edifícios. A área é permanentemente vistoriada pela defesa civil e as áreas mais críticas foram sinalizadas pelo mesmo órgão. Mas os moradores, desrespeitando tal sinalização, utilizam a área como estacionamento.

A área é considerada de alto risco, pois apresenta como evidência de instabilidade da área a presença de fraturas nas rochas, de degraus de abatimento, de árvores, postes e muros muito inclinados; também apresenta cicatrizes de escorregamento e presença de água na área, sejam provenientes da concentração de chuva em superfície, seja do lançamento de águas servidas ou da surgência de água nas áreas elevadas da área.

O topo da encosta apresenta encostas naturais com altura máxima de $8 \mathrm{~m}$ e inclinação no entorno dos $50^{\circ}$ e taludes de aterro com altura máxima de $3 \mathrm{~m}$ e inclinação de $85^{\circ}$. Na área verifica-se que o material pedogenizado é um pouco mais espesso que na base da encosta, mas vale ressaltar que nesse material encontram-se fragmentos de rocha inalterada.

O Morro dos Barbosas é ocupado por edificações de grande porte, apresentando sistema de drenagem precário, decorrente da concentração de água de chuva em superfície, do lançamento de águas servidas, e do vazamento de tubulações que escoam em direção a base da encosta. Outro fator desencadeador dos escorregamentos na área é o cultivo de espécies vegetais que acumulam água como as 


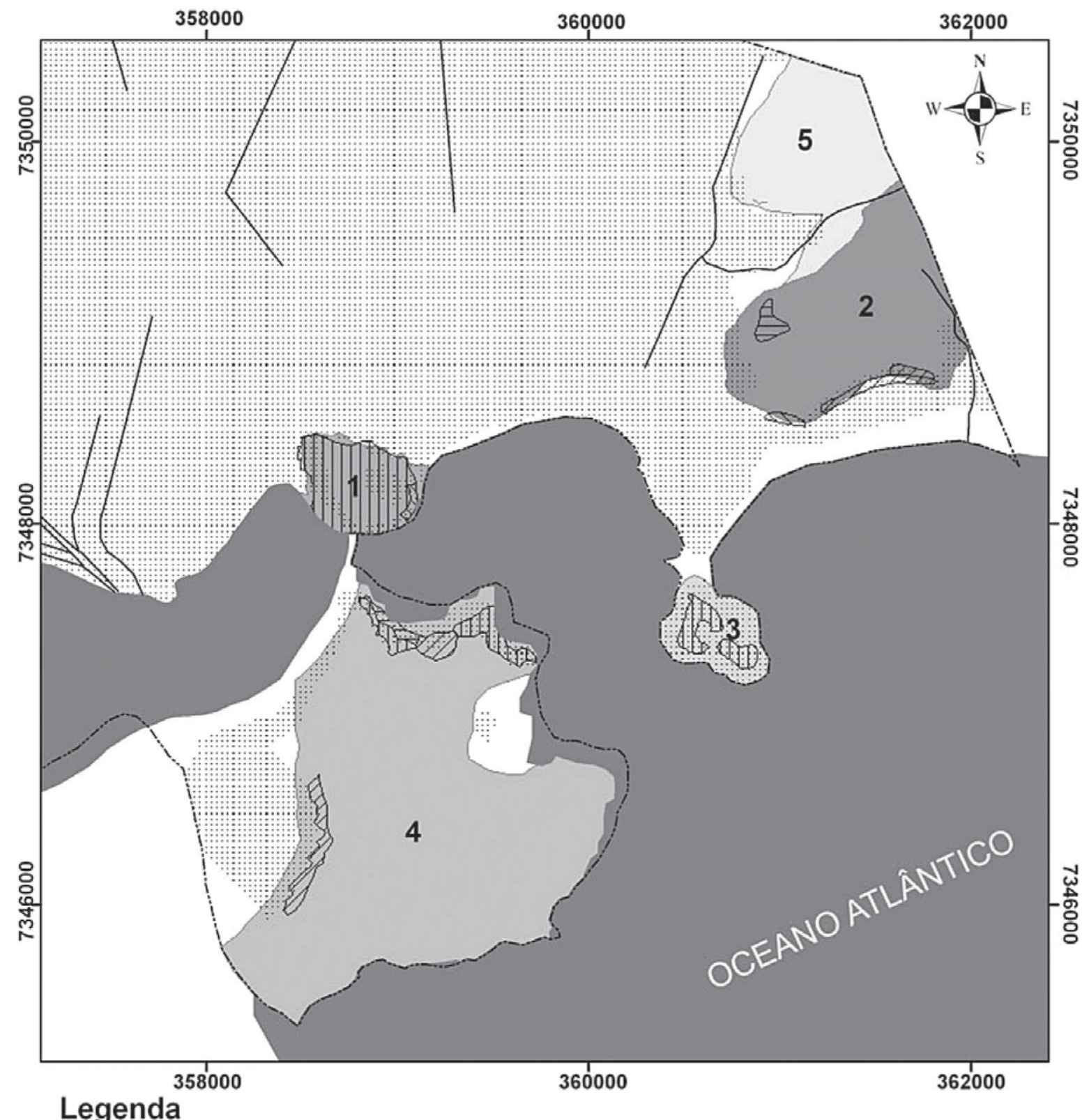

\section{Morros}

1 Morro dos Barbosas

2 Morro Itararé

3 Ilha Porchat

4 Morro Japuí

5 Morro Voturuá-Independência

\section{Risco a escorregamento Convenções Cartográficas}

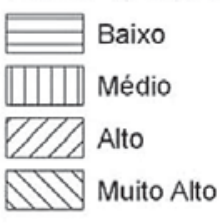

? Rede de Drenagem

S Oceano Atlântico

[....... Limite Municipal

Area Urbana

Figura 2. Mapa de Fragilidade a Escorregamentos dos setores de encosta da área urbana de São Vicente-SP. Elaboração: Raul Reis Amorim 
bananeiras e os bambuzais.

A área é considerada de médio risco, pois apresenta como evidência de instabilidade cicatrizes de escorregamentos em talude de aterro, processos erosivos, queda de blocos e rolamento de blocos, além de trincas em moradias (Figura 02).

Outra localidade de estudo situa-se no Bairro Itararé. Esse surgiu com o crescimento da cidade em direção a Pedreira Itararé e da linha da Estação de Ferro Sorocabana. Anterior a formação do bairro na década de 1920, na área existia junto ao morro uma pequena vila onde habitavam poucas famílias (RAMALHO et al, 2000).

A Santa Casa de Misericórdia cedeu parte de sua propriedade para a construção da Casa de Descanso para os Padres e da Capela Sagrado Coração de Jesus. A obra foi supervisionada pelo bispo Duarte Leopoldo e Silva da Cúria Metropolitana de São Paulo (op cit.).

Com o passar dos anos, a Capela começou a não comportar o aumento no número de fiéis, decorrentes do crescimento do bairro e das localidades adjacentes. A Cúria Metropolitana de São Paulo resolveu então construir ao lado do templo antigo a Igreja de São Pedro, o pescador (op. cit).

Durante as décadas de 1930-40 o bairro não sofreu transformações significativas. A partir da década de 1950, a área passou por grandes transformações sócio-espaciais, principalmente pela substituição dos casarões por edifícios de grande porte e a implantação de infra-estrutura, como saneamento básico e asfaltamento das ruas (op. cit).

Em 1997, a orla do Bairro Itararé foi reurbanizada, mediante a instalação de uma infra-estrutura destinada a atender ao turista, como quiosques, banheiros públicos e estrutura para realização de grandes eventos.

Nos setores de encosta do Bairro Itararé moram 3.242 habitantes, distribuídos em 1437 domi- cílios, sendo 224 casas, 1193 apartamentos e 18 cômodos. Todas as residências são atendidas por coleta de lixo e apresentam acesso pavimentado. Quanto ao abastecimento de água, cerca de 1.409 residências ligadas pela rede geral da SABESP e 10 residências são abastecidas por poços e nascentes. Outro serviço que contempla quase todas as residências das áreas de encosta do bairro é o saneamento básico, pois 1.397 residências estão ligadas à rede geral de esgoto e 38 domicílios fazem seu despejo de dejetos em fossas sépticas (IBGE, 2000).

Dentre os setores de encosta em estudo, o Morro Itararé é o que apresenta maior número de habitantes. É também a área mais verticalizada dentre as áreas de encosta e da cidade como um todo. $\mathrm{O}$ Bairro também apresenta baixa densidade de moradores por domicílio, já que 59,53\% dos domicílios é habitado apenas por 1 ou 2 moradores, 30,13\% ocupado por 3 ou 4 moradores. Já a distribuição de renda é menos concentrada que no Morro dos Barbosas e a Ilha Porchat, pois $16,41 \%$ dos domicílios mantém renda entre 3 e 10 salários mínimos e 8,89\% dos domicílios tem renda mensal acima de 10 salários mínimos. Outro dado importante é o maior percentual de população adulta dos setores de encosta, atingindo 66,38\%; e também apresenta o menor percentual de população jovem (em idade de 0 a 14 anos) totalizando 15,89\% da população total (Tabela 1).

O Morro do Itararé apresenta uma ocupação parcialmente consolidada, adjacente a áreas de ocupação consolidada. A densidade de ocupação varia entre 30 e $90 \%$, apresentando razoável infraestrutura. As vistorias de campo foram realizadas nas áreas que segundo a Defesa Civil de São Vicente, apresentam maiores riscos a escorregamentos. Foram escolhidos três pontos: Viela do Itararé, Rua da Constituição e Rua Coaraci Paranhos.

Na Viela do Itararé as encostam atingem até $100 \mathrm{~m}$ de altura, com $60^{\circ}$ de inclinação, enquanto nos taludes, a inclinação situa-se na proximidades de $90^{\circ}$ e altura máxima de $1,5 \mathrm{~m}$. As casas foram construídas a $2 \mathrm{~m}$ do talude, gerando risco constante a estas construções (Figura 02). Os solos são pouco 
espessos e têm contato abrupto com a rocha sã, predominando maciços rochosos com fraturas nãoalinhadas. As linhas de fratura favorecem a aceleração do intemperismo químico e físico, ou seja, a descamação, definida por Guerra e Guerra (2005, p. 195), como a "formação de cascas ou escamas sobre uma rocha, produzida pelo intemperismo”.

Já na Rua da Constituição e na Rua Coaraci Paranhos o risco a deslizamento é avaliado como alto, pois predominam matacões e maciços rochosos com fraturas não-alinhadas; inclinação em torno dos $80^{\circ}$ e altura máxima da encosta de 90m (Figura 2). É visível a presença de grandes cicatrizes de escorregamento que estão parcialmente cobertos por vegetação rasteira. A área está sujeita a ocorrência de escorregamento de material pedogenizado, queda e rolamento de blocos e desplacamento de material (Figura 3).

O Jornal “A Tribuna” ao longo dos anos de
2003, 2004 e 2005 vem documentando todos os casos que atingiram a área. O caso que mais preocupou os órgãos públicos é o caso de uma pensão da Rua Coaraci Paranhos, que foi interditada pela defesa civil por apresentar riscos à vida dos hóspedes. Entre 2003 e 2005 foram registrados 07 casos de escorregamento, sendo que nenhum causou prejuízos de vida.

A Ilha Porchat na atual divisão municipal por bairros também pertence ao Bairro Itararé. Durante sua fase inicial de ocupação do município serviu como base para as instalações da marinha, que visava inibir os ataques de inimigos. Em 1615, ocorreu a invasão de Santos e São Vicente pela Armada de Joris Van Spylbergen, sendo a Ilha Porchat o único ponto não ocupado pelos invasores (RAMALHO et $a l, 2000)$.

No final do século XVIII a Ilha passa a ser uma propriedade particular, tanto que cada um de
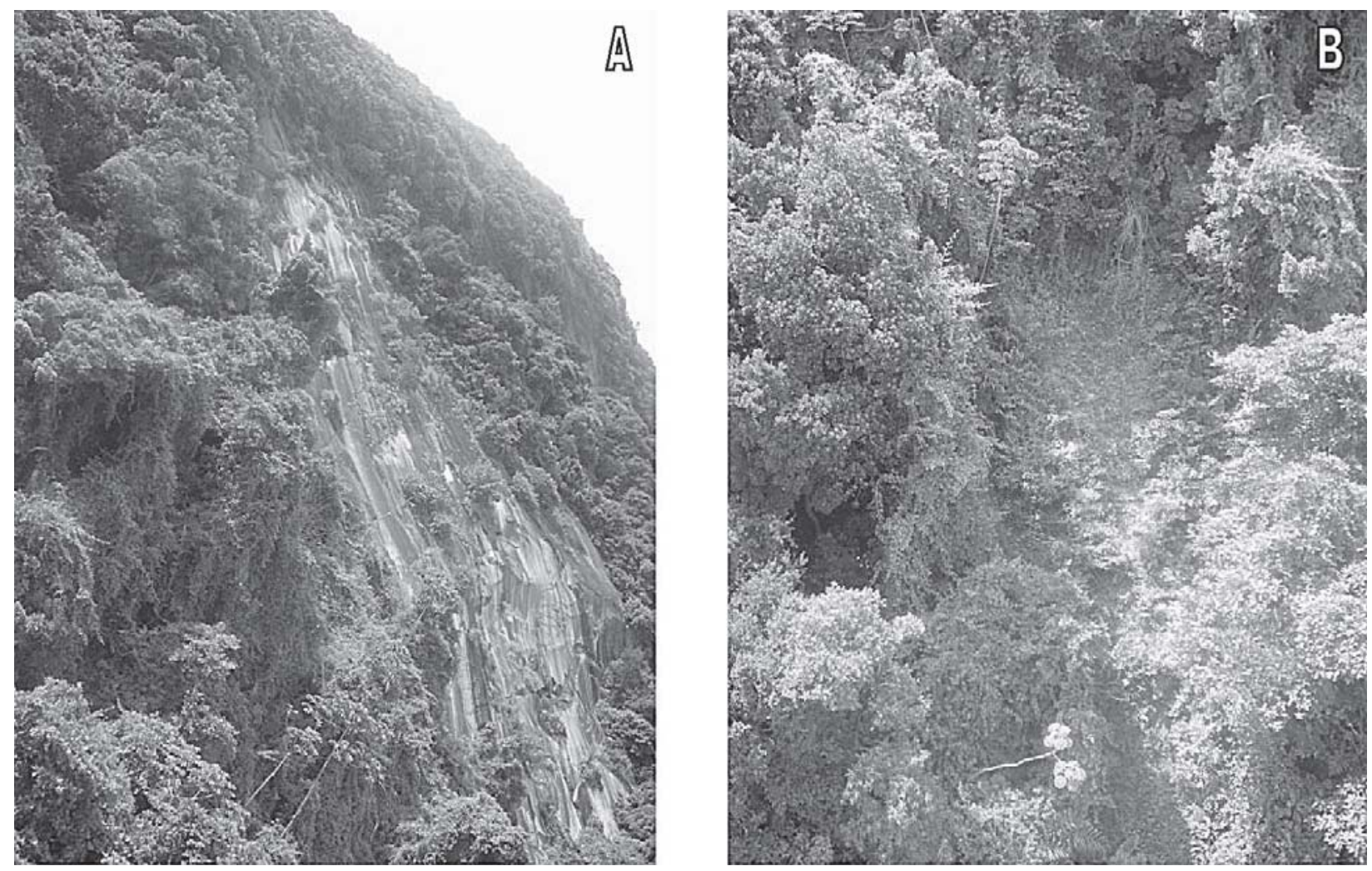

Figuras 3. A e B - Cicatrizes de Escorregamento no Morro do Itararé (2007).

Fonte: Raul Reis Amorim (Trabalho de Campo, 2007). 
seus donos lhe atribuiu um nome. O primeiro nome da Ilha foi "Ilha do Mudo", pois seu proprietário era um português mudo. Em 1812, outro português adquiriu a Ilha e deu-lhe o nome de "Ilha das Cabras”. Datam de 1870 as primeiras construções em alvenaria, pau-a-pique, taipa, madeira e pedra no contorno externo da ilha (op. cit).

A Ilha, em 1902, foi comprada pela família Porchat, que fixou residência na área. A residência de pedra construída na ilha anos depois passou a servir de sede para o Grande Cassino de Jogos e Diversões. Posteriormente, a família Porchat vendeu a Ilha para o senhor José Fracarolli Sobrinho, que construiu uma ponte de madeira facilitando o acesso ao casino. Com a proibição dos jogos no Brasil em 1946, o proprietário resolveu lotear a ilha e transformá-la em um bairro de luxo, onde deveriam ser respeitadas as seguintes regras: acesso controlado, proibição de edifício com mais de três andares, bem como hotéis e restaurantes. As instalações do casino foram ocupadas pelo Clube Ilha Porchat (op. cit).

As normas estabelecidas pelo Senhor José Fracarolli Sobrinho foram desrespeitadas e hoje na Ilha estão construídos edifícios com mais de 15 andares, hotéis, bares e restaurantes, tornando-se um dos principais destinos turísticos de São Vicente.

A área é ocupada por 513 habitantes distribuídos em 202 domicílios, sendo que destes 180 são apartamentos e 22 são casas. Todos os domicílios são atendidos pelos serviços básicos de infra-estrutura como, a coleta diária de lixo, o abastecimento de água encanada, a iluminação pública e o acesso com ruas pavimentadas. Quanto ao serviço de esgotamento sanitário, existe um predomínio de domicílios ligados à rede geral de esgoto, 198 domicílios, mas 4 domicílios na área despejam seus dejetos diretamente no mar (IBGE, 2000).

A distribuição sócio-demográfica é bastante semelhante ao Morro dos Barbosas e ao Morro Itararé. Uma parcela significativa das residências da área serve como casas de veraneio. Segundo a Tabela 1, verifica-se que $67,65 \%$ dos moradores estão em idade economicamente ativa (população entre 15 e 60 anos). Cerca de $60 \%$ dos domicílios são ocupados apenas por 1 ou 2 moradores, ou seja, a baixa densidade de moradores por domicílio. Outro dado importante é que $40,5 \%$ dos domicílios apresentam renda acima de 10 salários mínimos, revelando que o Bairro serve como residência a população de maior poder aquisitivo da cidade.

A área é sujeita aos escorregamentos de proporções média e baixa (Figura 2). As encostas naturas apresentam altura máxima de $10 \mathrm{~m}$ e inclinação de $50^{\circ}$. Já os taludes de corte têm altura máxima de $4 \mathrm{~m}$ e inclinação de $90^{\circ}$. Nesses taludes de corte encontramos cicatrizes de escorregamento. Outras evidências de instabilidade na área são: a presença de água devido à concentração de chuva em superfície; presença de fraturas nos maciços rochosos, solo residual e saprolito mantendo contato abrupto com as rochas, muros e postes inclinados além de trincas em terrenos e moradias. A presença de árvores, postes e muros muito inclinados evidenciam rastejamentos na área (Figura 4A e 4B).

O bairro Japuí está situado na porção continental do município, possuindo uma área territorial de $1.160 .000 \mathrm{~m}^{2}$, fazendo divisa com o município de Praia Grande. É constituído por um conjunto de loteamentos como o Parque Prainha (1928), Jardim Bechara (1960), Belverde Mar Pequeno (1963), e Jardim Recanto de São Vicente (1965).

A cerca de 300 metros da Ponte Pênsil, na Avenida Tupiniquins estão às ruínas conhecidas como “Porto das Naus”, onde em 1532, foi construído o primeiro Trapiche Alfandegário do Brasil, instalado por Martim Afonso de Sousa, logo após a fundação da Vila, e que, em 1580, foi transformado no Engenho de Açúcar, de propriedade de Jerônimo Leitão. As ruínas do engenho foi tombado pelo Conselho de Defesa do Patrimônio Histórico, Arqueológico, Artístico e Turístico do Estado de São Paulo (CONDEPHAAT), no ano de 1977 (RAMALHO et al, 2000).

Até 1962, o Bairro Japuí girava em torno do 

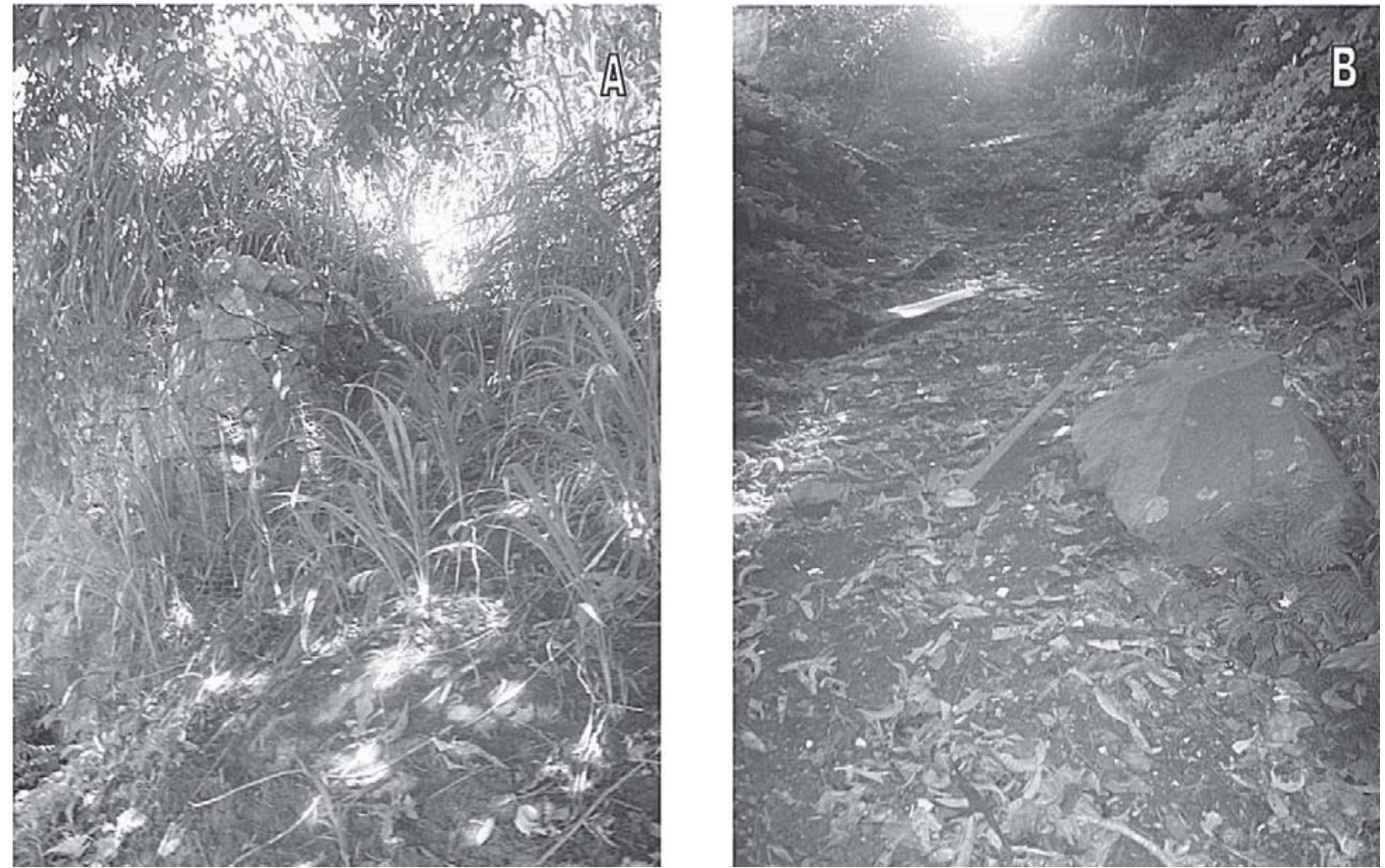

Figura 4. A - Rachaduras em muro em decorrência a um escorregamento; B - Cicatriz de escorregamento na Ilha Porchat (2007).

Fonte: Raul Reis Amorim (Trabalho de Campo, 2007).

Curtume Cardamone, mais antigas indústrias do país, que foi construída em 1891 por Luiz Pinto do Amorim e Jacob Emmerich, caracterizando-se um bairro essencialmente industrial. Em 1978, a indústria foi vendida a Carlo Farina, que entrou em falência em 1980. Dentre as causas da falência está o aumento dos custos na aquisição da matéria-prima, que passou a ser fornecida pelo Rio Grande do Sul depois do fechamento do matadouro de Santos. Além do Curtume, na área instalaram-se vários estaleiros para a construção e conserto de barcos (op. cit).

O bairro situa-se na área do Parque Estadual Xixová-Japuí, que é administrado pelo Instituto Florestal de São Paulo (IF).

Na década de 1990, o Japuí consolida-se como um bairro residencial, sendo importante frisar que apenas a base das encostas é diretamente ocupada. Para IBGE (2000) a área de cercania das encostas possui 2076 habitantes, distribuídos em 576 domicílios, sendo destes 528 casas, 46 apartamentos e 1 cômodo, tendo todos destem seu lixo coletado pelo serviço municipal de coleta. A localidade apresenta problemas de infra-estrutura como iluminação pública e pavimentação deficiente. Todas as casas têm água canalizada, sendo 540 residências recebem água da companhia estadual de saneamento e as outras 36 têm como fonte de água poços artesianos. Acredita-se que estes poços possam estar contaminados, pois 42 residências destinam seus efluentes em fossas sépticas e 11 em valas. O restante das residências, cerca de 522, estão ligadas ao serviço de saneamento público (IBGE, 2000).

Os setores de encosta do Bairro Japuí apresentam grande parte de sua área recoberta por fragmentos de Mata Atlântica. O Bairro é predominantemente residencial, pois na maior parte da área moram mais de 03 pessoas por domicílio (70,66\%). 
Outro dado importante é que 53\% dos domicílios apresentam renda entre 3 e 10 salários mínimos, o que comprova que a área é ocupada predominantemente pela classe média. A área apresenta o menor percentual de idosos (cerca de 8,92\%) e um dos maiores percentuais de população jovem da área de estudo (24,85\%). Mas o dado que se destaca é que a população adulta supera áreas como o Morro dos Barbosas (bairro de classe média-alta) e as encostas do Bairro Voturuá/Independência - a área mais popular entre as estudadas (TABELA 01).

Nesse bairro, as vistorias deram-se em dois pontos: na Avenida Engenheiro Saturnino de Brito e na Rua Benedito Calixto. Na primeira rua, encontrouse encostas naturais que atingiam entre 50 e $60 \mathrm{~m}$ de altura e apresentando entre $60^{\circ} \mathrm{e} 70^{\circ}$ de inclinação. Já os taludes de corte apresentam altura máxima de $3 \mathrm{~m}$ e inclinação variando entre $70^{\circ}$ e $90^{\circ}$. As encostas são formadas predominantemente por maciços rochosos que, pontualmente, estão cobertos por solo residual e saprolito. Nas encostas há evidências do processo de descamação (esfoliação tipo cebola) e intemperismo químico devido à infiltração da água das chuvas pelas faturas existentes.

A ação antrópica acelera os escorregamentos na área com o cultivo de bananeiras e o lançamento de efluentes. São indícios de instabilização: a presença de algumas trincas em moradias; degraus de abatimento; a presença de árvores, postes e muros inclinados. A área apresenta risco médio e pode desencadear escorregamento em encosta natural, talude de corte e aterro, queda de blocos, rolamento de bloco e rastejo (Figura 02).

A área que hoje abrange o Bairro VoturuáIndependência é decorrente da ocupação de parte do antigo sítio Itararé que pertenceu ao Sr. José Francisco Valença, e de um loteamento feito pela Irmandade da Santa Casa de Misericórdia de Santos, a partir de 1946. Tal loteamento deu origem a Vila Valença, onde mais tarde surgiram a Vila Misericórdia e a Vila Voturuá (RAMALHO et al, 2000).

Em homenagem as Comemorações do Ses- quicentenário da Independência do Brasil, no ano de 1972, a Vila Misericórdia, através do Projeto de Alteração de Nome aprovado pela Câmara Municipal em 1973, passou a chamar-se Jardim Independência (op. cit).

Nos domínios da Vila Voturuá, em 1954, foi fundado, na administração do Dr. Charles A. de Souza Dantas Forbes, o Horto Municipal de São Vicente, que tinha como objetivo inicial cultivar plantas ornamentais e servir de viveiro para diversas espécies vegetais, atendendo a demanda de arborização da cidade. Em 1991, através do Artigo 275 da Lei Orgânica do Município, o Horto Florestal foi transformado em Parque Ecológico. A área do parque abriga $850.000 \mathrm{~m}^{2}$, preservando significativo fragmento de Mata Atlântica, e também cedia um minizoológico (op. cit).

As encostas do Bairro possuem 2.931 habitantes, distribuídos em 775 domicílios, sendo destes 717 casas e 57 apartamentos, sendo todos tendo seu lixo coletado pelo serviço municipal de coleta. Á área de cercania das encostas do Japuí apresenta problemas de infra-estrutura, como iluminação pública e pavimentação deficiente. Em 750 residências, o abastecimento de água dá-se através de ligação com a rede que atende o município. Outras 18 residências têm como fonte de água poços artesianos e 6 são caracterizadas pelo IBGE como tendo outras fontes. Semelhante as áreas de encosta do Bairro Japuí, nessa área os poços artesianos também podem estar contaminados, já que 68 residências destinam seus efluentes em fossas sépticas e 48 em valas. Nessa área o percentual de casas ligadas à rede geral de esgoto é a menor, comparando com as demais áreas de encosta $(67,4 \%)$. Outro problema detectado na área é o destino do lixo. Enquanto nos demais setores de encosta, $100 \%$ do lixo é coletado pelo serviço de coleta municipal, nas encostas do Bairro Voturuá/ Independência, 19 domicílios declararam ao Censo 2000 que queimam seu lixo, 8 enterram na propriedade e 700 têm seus dejetos coletados pelo serviço de coleta municipal (IBGE, 2000).

Os setores de encostas do Bairro Voturuá/ 
Independência apresentam semelhanças quanto ao tipo de ocupação do Morro do Itararé e do Bairro Japuí, pois apenas a base destas é ocupada. A área apresenta baixo grau de verticalização, semelhante ao bairro Japuí, em que predominam casas de um e dois pavimentos. Cerca de 75\% das residências têm no mínimo 3 moradores. A área apresenta o maior percentual de população entre 0 e 14 anos (26,34\%) e em relação a população adulta (entre 15 e 60 anos) fica atrás percentualmente apenas do Morro dos Barbosas (63,63\%). Observa-se também na Tabela 01, que essa é a área que dentre as estudadas até então, apresenta menor concentração de renda por domicílio, pois cerca de $30 \%$ ganha até 5 salários mínimos, enquanto as residências que declararam ao Censo Demográfico 2000 que não possuem renda fixa (3,10\%) é igual aos domicílios com renda superior a 10 salários mínimos (IBGE, 2000).

As principais evidências da susceptibilidade da área a escorregamentos é a presença de matacões e maciço rochoso com $20 \mathrm{~m}$ de altura em alguns pontos. O material pedogenizado recebe periodicamente o lançamento de águas servidas em superfície. As encostas apresentam cobertura vegetal predominantemente rasteira e árvores que dificultaram a identificação de cicatrizes de escorregamento. Na área visitou-se uma residência que foi atingida por um rolamento de bloco em março de 2005. O evento não ocasionou nenhum prejuízo de vida nem material. O bloco foi retirado pela prefeitura e as cicatrizes desse rolamento estão cobertas por gramíneas. Segundo a Defesa Civil, os técnicos do Instituto de Pesquisas Tecnológicas (IPT), acompanhados da equipe da Defesa Civil, fazem vistorias periódicas no bairro, tanto nas áreas ocupadas por residências, como também no horto florestal, pois os viveiros dos animais ficam muito próximos das encostas.

A área apresenta árvores, postes e muros muito inclinados, as encostas naturas apresentam altura máxima de $70 \mathrm{~m}$ e inclinação de $90^{\circ}$, além de taludes de corte com máxima de $0,5 \mathrm{~m}$ e inclinação de $90^{\circ}$. Classifica-se a área como de risco médio (Figura 2).

\section{CONSIDERAÇÕES FINAIS}

Os escorregamentos são processos naturais que juntamente com os processos erosivos são responsáveis pela evolução das vertentes. Os setores de encosta do município de São Vicente apresentam elevada fragilidade natural a escorregamentos. Essa fragilidade está diretamente vinculada aos elevados índices pluviométricos, acentuada declividade e estado do material (área intensamente fraturada, com cobertura detrítica superficial e material rochoso exposto).

A ocupação de encostas no território brasileiro sempre é associada ao processo de favelização. Em São Vicente as favelas situam-se nas áreas ribeirinhas enquanto os bairros situados em encostas são habitados por moradores de elevado poder aquisitivo, casas de alto padrão e equipados de infraestrutura. Ressalta-se que o Morro do Bairro Independência/Voturuá é a única exceção, pois abriga habitantes de classe média-baixa, com casas de menor porte e apresentando algumas deficiências infra-estruturais.

O respeito às leis é fundamental para evitar catástrofes naturais. Todas as encostas da área de estudo apresentam declividade superior a $45 \%$, devendo estar florestadas. O ideal é evitar o avanço da ocupação nessas áreas de fragilidade tão acentuada.

Para as áreas já ocupadas, sugere-se que em todas as encostas da área urbana de São Vicente ocorra a implantação de um sistema de drenagem superficial, tais como canaletas, rápidos, caixas de transição, escadas d'água, etc. Vê-se que é necessário proteger os taludes que apresentam solo exposto com a plantação de gramíneas e o desmonte de blocos rochosos e matacões. Todas essas medidas são necessárias para evitar prejuízos de vida e prejuízos materiais.

Para a Ilha Porchat e o Morro dos Barbosas também se sugere a construção de um sistema de drenagem de subsuperfície (trincheiras drenantes, poços de rebaixamento). A Rua Constituição, situada no bairro Itararé, é considerado o ponto de maior 
risco a escorregamento e, objetivando minimizar a ação de um escorregamento na área, sugere-se que em seus vários pontos sejam construídas estruturas de contenção localizada, como chumbadoras, tirantes, microestacas e muros de contenção passivos de pequeno porte.

\section{REFERÊNCIAS BIBLIOGRÁFICAS}

ARAUJO, G. H. S.; ALMEIDA, J. R; GUERRA, A. J. T. Gestão ambiental de áreas degradadas. Rio de Janeiro: Bertrand Brasil, 2005.

COELHO, M. C. N. Impactos ambientais em áreas urbanas - teorias, conceitos e métodos de pesquisa. In: GUERRA, A. J. T.; CUNHA, S. B. (org). Impactos ambientais urbanos no Brasil. Rio de Janeiro: Bertrand Brasil, 2001. 19-45 p.

COMDEC. Arquivo da Comissão da Defesa Civil de São Vicente-SP. São Vicente, 2007.

IAC, Instituto Agronômico de Campinas. Mapas Pedológicos do Estado de São Paulo: legenda expandida. Embrapa. Campinas, 1999.

MACIEL, G. C. Zoneamento Geoambiental do Município de São Vicente (SP), Utilizando o Sistema de Informação Geográfica - SIG. Dissertação de Mestrado da USP - São Carlos, Editora da USP, São Carlos (SP), 2001.

MATEO RODRIGUEZ, J. M.; SILVA, E. D.; CAVALCANTI, A. P. B. Geoecologia da paisagem: uma visão geossistêmica da análise ambiental. Fortaleza: EDUFC, 2002.

RAMALHO, R. et al. A história de São Vicente contada através dos Bairros. São Vicente: Secretaria de Educação de São Vicente, 2000.

RODRIGUEZ, J, M. Análise e síntese da abordagem geográfica da pesquisa para o planejamento ambiental. Revista do Departamento de Geografia da FFLCH/USP. São Paulo, v. 9. 1994.
SOUZA, G. B. N. Degradação ambiental e a ocupação do solo na várzea do Rio Ouricuri, Capanema (PA). Revista GeoUerj. Rio de Janeiro, edição especial, 800-807p., novembro/2004.

SUGUIO, K; MARTIN, L. Mapa geológico: Folha Santos. São Paulo: DAEE/USP/FAPESP. Escala 1:100.000, 1978.

A TRIBUNA. Deslizamento de Terra na Biquinha causam danos ao turismo em São Vicente. Santos: 01/02/1995. 